\title{
Nuevos materiales poliméricos derivados de fuentes renovables
}

\section{New Polymeric Materials derived from renewable sources}

\author{
Lopretti, Mary ${ }^{(1)(2)}$, Gandini, Alessandro ${ }^{(3)}$ \\ (1) Laboratorio de Bioquímica y Biotecnología, Facultad de Ciencias, Universidad de la República, Uruguay - (2) Departa-
} mento de Proyectos de Bioprocesos, Laboratorio Tecnológico del Uruguay, LATU, Uruguay - ${ }^{(3)}$ Chemistry Department, University of Aveiro, Portugal (2007-2011).

Contacto: mlopre@latu.org.uy

Recibido: 14/6/2012 - Aprobado: 30/9/2012

\begin{abstract}
$\underline{\text { Resumen }}$
En las últimas décadas se ha trabajado sobre el concepto de la Biomásica como alternativa de la Petroquímica. Existe un creciente interés en el uso de materiales renovables para energía y nuevos materiales. En este trabajo se estudió la síntesis de nuevos materiales poliméricos derivados de materiales renovables, especialmente lignina, por acción de sistemas enzimáticos oxidativos derivados de G. trabeum y P. ostreatus. El propósito fue la optimización y modelización de la producción de enzimas por fermentación semisólida. Se estudió la actividad en ligninas kraft y organosolv y se observó disminución del peso molecular e incremento de los grupos carboxilo. Se concluye que para los dos hongos el origen de la lignina es irrelevante. Sin embargo, aparecen diferencias cuando se utilizan compuestos modelo de lignina. Se ha observado diferente crecimiento y aparición de sistemas enzimáticos, responsables del peso molecular y el grado de oxidación de los grupos funcionales. Se considera que la producción estandarizada de enzimas favorecerá en el futuro su uso industrial de "unidades definidas" o "bloques". En trabajos futuros se estudiará la cinética de producción.
\end{abstract}

Palabras clave: Lignina, conversión biológica, enzimas, polímeros.

\begin{abstract}
$\underline{\text { Abstract }}$
In the last years it has been worked on the concept of Biomasic as an alternative to Petroquimic. An increasing interest of renewable resources in the area of energy and materials exists. In this work the synthesis of new polymeric materials derived from several renewable sources with emphasis in the valuation of lignins, with an oxidative systems enzymatic presents in two stocks of fungi G. trabeum and P. ostreatus in different combinations starters, were studied. The purpose was the optimization and modeling of the enzimatic production by semi solid fermentation process. The activity on Kraft and Organosolv lignins was analized and it was observed diminution of the molecular weight and an increase of the carbonyl groups in the tests with models and with lignins. We conclude that for both fungus the origin of the lignin as a carbon source is irrelevant. We consider that the production of standardized enzymatic extracts can be an interesting contribution at the time of making modifications in industrial lignins to obtain "well-known functional units". In future works the kinetic of modification will be studied with the objective to make possible a future industrial application.

Keywords: Lignin, biological conversion, enzymes, polymers.
\end{abstract}

\section{Introducción}

\section{Importancia del estudio de modificaciones bioquímicas de la lignina}

En las últimas décadas se ha trabajado sobre el concepto de la "Biomásica" como alternativa de la "Petroquímica".

Este concepto de desarrollar a partir de Biomasa (biopolímeros) productos energéticos como biocombustibles, productos químicos como ácidos orgánicos, alcoholes, aromas, entre otros, productos farmacéuticos, materiales poliméricos híbridos, etcétera, permite pensar en una nueva área de biorefinería que valoriza diferentes partes de las moléculas que constituyen la biomasa, ya sea por extracción y/o por transformación en productos de mayor valor agregado. En el estudio de modificaciones se halla un gran desafío: la separación y modificación de los biopolímeros en forma selectiva. Esto permitiría definir un prototipo de proceso para obtener productos monoméricos $\mathrm{u}$ oligoméricos estandarizados que tengan un valor comercial en sí mismos o sean "bloques" o "unidades" que se transforman en materia prima para nuevas copolimerizaciones en materiales híbridos.

Dentro de los materiales lignocelulósicos se encuentran tres compuestos fundamentales, celulosa, hemicelulosas y lignina, y uno de los desafíos más grandes es modificar y valorizar la molécula de lignina.

Con un tratamiento adecuado estos materiales pueden transformarse en productos de mayor valor agregado, con la etapa de fraccionamiento como la de mayor importancia. Para que el fraccionamiento sea viable es necesario que la etapa tenga lugar sin destrucción o pérdida de los componentes involucrados. Un ejemplo de esto es la separación de la lignina, que puede hacerse en forma química, Kraft, organosolv, por ejemplo, o en forma selectiva, utilizando sistemas microbianos o enzimáticos.

Una vez producida la etapa de fraccionamiento vía delignificación, los procesos de hidrólisis y fermentación permiten obtener los 
distintos productos del árbol llamado "árbol de los lignocelulósicos".

De los materiales lignocelulósicos es posible obtener, a partir de los carbohidratos, furfural, xilosas, glucosa, derivados de celulosa, pulpa y combustibles, entre otros, y a partir de las ligninas, vainillina, dimetilsulfuro, fenoles, resinas termorrígidas, antioxidantes, matrices para geles y fertilizantes, etcétera.

De estas aplicaciones vemos en general que la celulosa se usa como pulpa para papel, o se convierte en derivados como rayón, celofán, acetato de celulosa, CMC (carboximetilcelulosa) o butirato de celulosa (Gandini, 2002).

La hemicelulosa acompaña la celulosa en la pulpa de papel o se transforma a furfural. Los productos con fines energéticos se hidrolizan a glucosa para luego ser fermentados.

A su vez, la lignina presenta algunos usos actuales: moléculas de bajo peso molecular, como vainillina, fenoles y derivados; uso en solución como dispersante, estabilizante de emulsiones, agente complejante, precipitante o coagulante; uso para la producción de diversos polímeros, tales como resinas termorrígidas; uso como matriz para absorción o intercambio iónico; conversión mediante carbonización y pirólisis en carbón activado (Gandini, 2002).

En un trabajo previo, Agosin et al. $(1989,1990)$ describen que el $5 \%$ de la lignina disponible se utiliza con estos fines, por lo que resta gran cantidad por utilizar.

Se hace necesario el estudio de nuevos sistemas de transformación biológica, tanto por hongos como por bacterias, ya que utilizando materiales naturales y procesos biológicos (microorganismos o enzimas) resulta posible desarrollar una línea de productos naturales y con tecnologías limpias.

El estudio de estos procesos requiere el conocimiento de la estructura de la lignina, su localización y los procesos naturales conocidos hasta el momento.

En cuanto a la molécula de lignina, es preciso conocer su localización en la estructura de los tejidos lignocelulósicos (Higuchi, 1980), y también su compleja estructura en cuanto a los tipos de enlaces y los grupos funcionales que la caracterizan. Se debe hacer referencia necesariamente a la técnica de extracción y recuperación de la lignina, dado que se obtienen ligninas de características diferentes (Gandini, 2002). Se muestra en la Figura 1 la representación del polímero lignina.

Los procesos degradativos que modifican la estructura de lignina, tanto fisiológicos como bioquímicos, son de fundamental importancia para el estudio de su transformación.

\section{Aspectos biológicos y bioquímicos de la degradación de lignina}

Estos procesos bioquímicos de degradación y transformación están relacionados con la fisiología y bioquímica de los microorganismos que colonizan estos materiales.

Entre los microorganismos más estudiados, se encuentran los llamados hongos de pudrición blanca, que incluyen varios cientos de especies de Basidiomycetes y unas pocas especies de Ascomicetes.

Estos hongos son los más estudiados y se ha demostrado que degradan rápidamente la mayor parte de los componentes de la madera a $\mathrm{CO} 2$ y agua.

Los carbohidratos y ligninas son degradados simultáneamente durante la degradación de la madera, y existen algunos hongos que parecen tener preferencia en degradar los componentes de la lignina, como $P$. chrysosporium, C.versicolor y P. ostreatus.

Otro grupo de hongos, llamados hongos de pudrición parda, representados por numerosas especies de Basidiomycetes, degradan la celulosa y hemicelulosa y presentan solamente una pequeña modificación de la lignina. Sin embargo, se han descrito especies con una intensa actividad oxidativa, que producen una demetoxilación y una amplia hidroxilación en la posición 2 del anillo fenólico, y son las modificaciones más importantes producidas por estos hongos (Agosin et al., 1989, 1990; Hojas, 1999; Venica, 1997).

Los procesos anteriores conducen a la formación de O-difenoles (moieties), que por autooxidación producen cromóferos del tipo quinina. La ruptura de los anillos es mínima, pero genera cambios en el contenido de carbonilos y carboxilos, por ejemplo con L. trabea.

El equipo de Kirk \& Connors (1976), en sus varios trabajos en el tema, ha demostrado que la demetoxilación es el mayor cambio producido sobre la lignina, y los microorganismos que más se han estudiado son Poria cocos y Gloeophyllum trabeum. En resumen, la principal diferencia entre hongos blancos y hongos de pudrición parda es que los últimos tienen muy poca habilidad de metabolizar los anillos aromáticos.

Finalmente, otro grupo corresponde al de los llamados hongos "soft-rot", que incluye varios Ascomicetes y hongos imperfectos. Para estos organismos se ha demostrado que degradan la mayoría de los compuestos, incluida la lignina.

Entre los géneros estudiados se hallan: Graphium, Monodictys, Allescheria, Paecilomyces, Populospora y Thielevia, los cuales degradan lignina.

Estas especies degradan lignina más efectivamente en maderas duras que en maderas blandas. En los estudios se emplean ${ }^{14} \mathrm{C}$ de cadenas laterales a los anillos y DHPs con metoxilos marcados, y 14 ligninas que permiten ver el mecanismo de acción.

Han sido estudiados otros hongos, como Fusarium solari y Aspergillus fumigotus, que degradan ligninas y modelos de ligninas.

La degradación por acción de bacterias se comenzó a estudiar más recientemente; algunos cultivos de Nocardia muestran capacidad de degradar compuestos modelo sintéticos, o ${ }^{14} \mathrm{C}$ - DHP o ${ }^{14} \mathrm{C}$ ligninas de lignocelulosa.

La conversión del anillo, cadena lateral y grupos metoxilos de DHP a ${ }^{14} \mathrm{CO} 2$ encontrada por algunos autores fue 5.15 y $13 \%$, respectivamente (Vicuña, 1988).

Se han descrito cultivos de Bacillus sp. y algunos cultivos de Streptomyces que aparecen degradando ${ }^{14} \mathrm{C}$ lignina de lignocelulósicos. Streptomyces flavovirens degrada totalmente la molécula y ha sido estudiado por pérdida de peso y microscopía electrónica.

Arthrobacter sp. degrada material lignificado de maní, Flavobacterium, Pseudomonas y Acromonas spp degradan ligninas ácidas, mientras que las Xanthomonas $s p$ degradan el $77 \%$ de ligninas dioxano a C y energía en 15 días (Lopretti, 1999).

Se ha demostrado que las ligninas Kraft de peso molecular mayor que 1500, son degradadas por Pseudomonas y Acinetobacter (Lopretti, 1999).

\section{Aspectos bioquímicos de la degradación}

La forma de degradación por hidrólisis de distintos enlaces $\mathrm{y}$ cambios en los grupos funcionales, o diferencias en los pesos moleculares, no es conocida con exactitud para todos los microorganismos que actúan.

En los procesos degradativos se pueden reconocer algunos compuestos que están siempre presentes, como los ácidos ferúlico, vanílico, siríngico, p-hidroxibenzoico, p-hidroxicinámico y otros compuestos como vanillina, coniferaldehído, guaiacilglicerol, etcétera.

Todos estos son sustrato para microorganismos que colonizan el suelo y, además, bacterias, levaduras y hongos. También son unidades que pueden ser utilizadas en nuevas copolimerizaciones.

Para el caso de compuestos metoxilados se ha visto que en cultivos estacionarios con algunas especies de Pseudomonas después de 60 días aparece una disminución de los grupos metoxilo.

Varias enzimas se han reportado como responsables de estas modificaciones. La O-demetilasa cataliza la demetilación de compuestos aromáticos metilados, liberando formaldehído, mientras que las lacasas liberan metanol. Las unidades metilo de ligninas son degradadas preferentemente por microorganismos que metabolizan compuestos de $\mathrm{C} 1$.

El metanol es oxidado a formaldehído seguido de oxidaciones a ácido fórmico y dióxido de carbono.

Mediante estos procesos se obtiene energía que es almacenada en forma de ATP. Alternativamente, los compuestos $\mathrm{C} 1$ son incorporados 
en el material celular por la vía de la ruta de asimilación de C1.

En este trabajo se busca estudiar consorcios de microorganismos con diferentes capacidades de síntesis de enzimas, complementarias entre sí, para la degradación específica de lignina, y obtener las denominadas "unidades fenólicas para copolimerización" en un sistema repetible y escalable que permita su uso comercial. El estudio se desarrolla en un sistema de fermentación semisólida, que resulta más afín para los hongos, similar al medio natural, en lugar de utilizar una producción en sistema sumergido.

\section{Materiales y Métodos}

\section{Producción de "unidades fenólicas" de lignina por fermentación semisólida}

Se cultivaron conjuntamente $G$ trabeum y Pleurotus ostreatus en un medio para hongos PDB donde se adicionó $0,5 \% \mathrm{w} / \mathrm{v}$ de Lignina Kraft en un caso (a) y Lignina organosol en otro (b), en presencia de $0,1 \mathrm{ml}$ de sales de Kirk y $3 \%$ de extracto de levadura. El medio así preparado se inoculó con los hongos propagados por separado anteriormente en medio PDB durante 7 días en una proporción de $5 \% \mathrm{w} / \mathrm{v}$.

En estas condiciones, después de 7 días de crecimiento conjunto, el cultivo fue introducido en un sistema de fermentación semisólida, utilizando $500 \mathrm{~g}$ de material lignocelulósico proveniente de Eucaliptus grandis (los dos materiales fueron suministrados por la Ecole Française de Papeterie et des Industries graphiques, de Grenoble).

Durante el proceso la humedad fue de $70 \%$ y fue necesario remover el material cada 5 días para incorporar oxígeno.

Cada cultivo permaneció a temperatura ambiente por 30 días, para luego obtener por lixiviación con solución de $\mathrm{Na} \mathrm{Cl} 0,09 \%$ y posterior prensado un extracto que correspondió a $100 \mathrm{ml}$. El material sólido también fue recuperado y se secó a temperatura ambiente.

En el extracto se evaluó la producción de enzimas sintetizadas en el proceso y los derivados fenólicos obtenidos por la acción de estas enzimas sobre la lignina presente en el sustrato sólido.

\section{Evaluación de la producción de fenoles}

Se realizaron barridos espectrofotométricos UV-Visible entre 230 a $600 \mathrm{~nm}$, estableciendo los cambios en las lecturas por las oxidaciones producidas, y una determinación de fenoles, utilizando una curva estándar de fenol.

\section{Distribución de PM de los fenoles obtenidos por cromatografía de gel permeación (GPC)}

La cromatografía de gel permeación se realizó montando una columna de Sephadex LH-20 (Pharmacia). El gel fue preparado con alcohol isopropílico: agua destilada en relación 1:1 como solvente, y la columna tenía una geometría de $20 \mathrm{~cm} \times 2 \mathrm{~cm}$.

El punto de exclusión fue determinado con azul dextrano (PM $2000000 \mathrm{~g} / \mathrm{mol}$ ), medido a $525 \mathrm{~nm}$.

El punto de inclusión se midió con fenol $(\mathrm{PM}=94.11 \mathrm{~g} / \mathrm{mol})$, medido a $275 \mathrm{~nm}$. Las muestras fueron preparadas solubilizando $0,2 \mathrm{ml}$ de lignina en $0,2 \mathrm{ml}$ de solvente. Se colocaron $0,2 \mathrm{ml}$ de esta muestra en la columna.

Las fracciones recolectadas fueron de $2 \mathrm{ml}$, con un flujo de 0,06 $\mathrm{ml} / \mathrm{min}$, las cuales fueron medidas a $280 \mathrm{~nm}$ y se obtuvo el perfil de elución. Las fracciones obtenidas responden a oligómeros de lignina (fenoles modificados).

\section{Determinación de la actividad enzimática}

El extracto obtenido en la fermentación semisólida fue filtrado y se realizaron diferentes determinaciones de actividades enzimáticas propias de los microorganismos crecidos en este sistema. Las actividades estudiadas fueron las que se detallan a continuación.

\section{Actividad Lignina Peroxidase}

Esta actividad fue determinada por el Método de Tien \& Kirk (1984). Se utilizó alcohol veratrílico 0,01 M como sustrato en buffer tartrato de sodio $(0,1 \mathrm{M}, \mathrm{pH} 3.0)$ El ensayo se realizó utilizando 1 $\mathrm{ml}$ de esta solución y $0,1 \mathrm{ml}$ del extracto enzimático obtenido de la fermentación. La reacción se inició agregando $4 \mathrm{mM}$ de $\mathrm{H} 2 \mathrm{O} 2$ y continuó durante $1 \mathrm{~h} \mathrm{a} 37^{\circ} \mathrm{C}$. Fue monitorizada midiendo el incremento de absorbancia a $310 \mathrm{~nm}(\mathrm{emax}=9300 / \mathrm{M} . \mathrm{cm})$.

\section{Actividad Laccasa}

Esta actividad se determinó midiendo la oxidación de ABTS en buffer glicina- $\mathrm{HCl}(\mathrm{pH} 3,0)$ a $420 \mathrm{~nm}(\mathrm{emax}=36000 / \mathrm{M} . \mathrm{cm})$. Para el ensayo se utilizó $2 \mathrm{ml}$ de solución de ABTS $0.1 \mathrm{M}$ a pH 3, a la cual se le adicionó $0,1 \mathrm{ml}$ del extracto enzimático obtenido de la fermentación y se incubó durante $1 \mathrm{~h}$ a $35^{\circ} \mathrm{C}$.

\section{Actividad Demetilasa}

Se aplicó el método de medida utilizando un compuesto modelo metoxilado. La reacción se siguió por medidas espectrofotométricas y por determinación del cambio en el espectro.

Para el ensayo se utilizó $2 \mathrm{ml}$ de $0,1 \mathrm{M}$ de 3,4,5-trimetoxy benzaldehyde (Aldrich), pH 4, al cual se le agregó $0,1 \mathrm{ml}$ del extracto enzimático obtenido de la fermentación. Se incubó a $30{ }^{\circ} \mathrm{C}$ y se monitorizó midiendo la disminución del sustrato por espectrofotometría UV -Visible a $354 \mathrm{~nm}$.

\section{Determinación de proteínas}

La determinación de proteínas se realizó por el método de la Reacción de Folin, muy utilizado para la determinación de proteínas en muestras biológicas (Lowry et al., 1951). Primero, las proteínas son pretratadas con ión cobre en solución alcalina, y luego los aminoácidos aromáticos presentes en la muestra reducen el ácido fosfomolibdato fosfotúngstico presente en el reactivo de Folin. Se desarrolla un color azul que es cuantificado por espectrofotometría midiendo la absorbancia a $750 \mathrm{~nm}$

\section{Resultados}

\section{Actividad enzimática obtenida}

Del análisis de actividad en los extractos filtrados de la producción de fenoles modificados se obtuvieron los resultados que se muestran en la Tabla 1. 


\begin{tabular}{|l|c|c|c|}
\hline $\begin{array}{l}\text { Actividad enzimática } \\
\text { con Lig Kraft }\end{array}$ & $\begin{array}{c}\text { 5 días } \\
\text { de cultivo }\end{array}$ & $\begin{array}{c}\text { 15 días } \\
\text { de cultivo }\end{array}$ & $\begin{array}{c}\text { 30 días } \\
\text { de cultivo }\end{array}$ \\
\hline Lig peroxidasa & 10 & 18 & 22 \\
\hline Laccasa & 5 & 15 & 20 \\
\hline Demetilasa & 0 & 4 & 15 \\
\hline A & & & \\
\hline
\end{tabular}

\begin{tabular}{|l|c|c|c|}
\hline $\begin{array}{l}\text { Actividad enzimática } \\
\text { con Lig Organosolv }\end{array}$ & $\begin{array}{c}\mathbf{5} \text { días } \\
\text { de cultivo }\end{array}$ & $\begin{array}{c}\text { 15 días } \\
\text { de cultivo }\end{array}$ & $\begin{array}{c}\text { 30 días } \\
\text { de cultivo }\end{array}$ \\
\hline Lig peroxidasa & 8 & 18 & 20 \\
\hline Laccasa & 8 & 15 & 18 \\
\hline Demetilasa & 0 & 6 & 15 \\
\hline B & & & \\
\hline
\end{tabular}

\begin{tabular}{|l|c|c|c|c|}
\hline $\begin{array}{l}\text { Volumen de } \\
\text { elución }(\mathbf{m l})\end{array}$ & $\begin{array}{c}\text { L-Kraft } \\
\text { sin tratar }\end{array}$ & $\begin{array}{c}\text { L-Kraft } \\
\text { tratada }\end{array}$ & $\begin{array}{c}\text { L-organosolv } \\
\text { sin tratar }\end{array}$ & $\begin{array}{c}\text { L-organosolv } \\
\text { tratada }\end{array}$ \\
\hline $\mathbf{4}$ & & & 0,45 & \\
\hline $\mathbf{6}$ & 0,89 & 0,49 & 0,24 & 0,54 \\
\hline $\mathbf{8}$ & & & & 0,5 \\
\hline $\mathbf{1 0}$ & 0,21 & 0,29 & 0,18 & 0,32 \\
\hline $\mathbf{1 2}$ & 0,13 & 0,32 & & \\
\hline $\mathbf{1 4}$ & & & & 0,10 \\
\hline $\mathbf{1 6}$ & & 0,11 & & 0,07 \\
\hline $\mathbf{1 8}$ & & & & \\
\hline $\mathbf{2 0}$ & & & & \\
\hline
\end{tabular}

Tabla 1. Actividad enzimática (UE/ml) obtenida en Sistema semisólido de G. trabeum y $P$. ostreatus en cultivo con Lignina Kraft (a); Sistema semisólido de $G$. trabeum y $P$. ostreatus en cultivo con Lignina organosolv (b).

Tabla 3. Distribución de fracciones oligoméricas de lignina por Gel filtración con gel de Sephadex LH-20 (Pharmacia), alcohol isopropílico: agua destilada en relación 1:1. Las medidas fueron hechas a 280 $\mathrm{nm}$. Las muestras fueron obtenidas sin tratamiento y con tratamiento fúngico durante 30 días. Se determinó para ligninas Kraft y ligninas organosolv.

Estudio Espectrofotométrico de los fenoles modificados obtenidos

Se muestra una extensa oxidación en la lignina tratada y se obtienen productos de la depolimerización y oxidación. Estos resultados se incluyen en la Tabla 2.

\begin{tabular}{|l|c|c|c|c|}
\hline Muestra & $\mathbf{2 8 0} \mathbf{n m}$ & $\mathbf{3 1 0} \mathbf{n m}$ & $\mathbf{3 5 4} \mathbf{n m}$ & $\mathbf{3 7 5} \mathbf{~ n m}$ \\
\hline $\begin{array}{l}\text { Lignina (a) sin } \\
\text { tratamiento }\end{array}$ & 0,84 & 0,01 & 0,12 & 0,08 \\
\hline $\begin{array}{l}\text { Ligninas (a) } \\
\text { solubilizadas }\end{array}$ & 0,42 & 0,32 & 0,21 & 0,09 \\
\hline
\end{tabular}

\begin{tabular}{|l|c|c|c|c|}
\hline Muestra & $\mathbf{2 8 0} \mathbf{n m}$ & $\mathbf{3 1 0} \mathbf{n m}$ & $\mathbf{3 5 4} \mathbf{n m}$ & $\mathbf{3 7 5} \mathbf{~ n m}$ \\
\hline $\begin{array}{l}\text { Lignina (b) sin } \\
\text { tratamiento }\end{array}$ & 0,64 & 0,08 & 0,1 & 0 \\
\hline $\begin{array}{l}\text { Ligninas (b) } \\
\text { solubilizadas }\end{array}$ & 0,38 & 0,42 & 0,21 & 0,1 \\
\hline
\end{tabular}

Tabla 2. Se muestran las absorbancias obtenidas de las soluciones utilizadas de ligninas Kraft (a), Organosolv (b), sin tratamiento y ligninas a y b solubilizadas por tratamiento enzimático con 100 UE de Lig-peroxidasa, 100 UE de Lacassa y 50 UE de Demetilasa. Esta actividad de enzima fue promedio de las actividades enzimáticas que se obtuvieron en el total del lixiviado para cada sustrato (Kraft y Organosolv).

\section{Distribución de PM en Gel permeación (GPC)}

La distribución de fracciones de diferente PM cambia cuando se trabaja en un sistema de fermentación semisólida. Se muestran en la Tabla 3 las absorbancias obtenidas en la distribución de los oligómeros presentes en ligninas sin tratamiento y en ligninas con tratamiento fúngico.

Tanto para las ligninas Kraft como organosolv los perfiles espectrofotométricos indican que aparecen fracciones con el mismo perfil de elución, en las ligninas sin tratamiento y las tratadas en FSS, pero la concentración es menor en las fracciones que tienen una velocidad de aparición temprana, las fracciones de mayor peso molecular.

En ambos casos aparecen también fracciones de menor peso molecular que no se hallaban en las ligninas sin tratamiento, causadas por las enzimas presentes.

\section{Conclusiones}

Estos estudios demuestran que es factible preparar consorcios enzimáticos capaces de modificar por depolimerización oxidativa un polifenol como la lignina, dando siempre oligómeros fenólicos estables denominados "unidades definidas" o "bloques". Estas unidades que tienen absorbancia a $280,310,354$ y $375 \mathrm{~nm}$ se repiten y cuentan con la capacidad de ser utilizadas para copolimerizar y obtener materiales poliméricos combinados o híbridos, como poliuretanos reforzados, poliésteres y adhesivos, por ejemplo.

Esto genera la posibilidad de sintetizar diferentes tipos de edificaciones en bloques para la preparación de nuevos materiales poliméricos basados en recursos renovables.

Es viable la obtención de monómeros como aldehído veratrílico, fenol, ácido vanílico y vainillina, como "unidades definidas" que tienen su valor comercial en sí mismas o se pueden utilizar en materiales compuestos nuevamente sintetizados. Finalmente, resulta posible definir que nos encontramos ante un consorcio de hongos formado por G. trabeum y P. ostreatus que es efectivo para este proceso de obtención de unidades fenólicas, como también lo es el diseño de producción desarrollado por (FSS), fermentación semisólida.

En futuros trabajos se realizarán identificaciones precisas de las unidades y se trabajará en algunos ejemplos de aplicación. 


\section{Referencias}

- AGOSIN, E.; BLANCHETE, R. Characterization of palo podrido, a natural process of delignification in wood. En: Appl. Environ. Microbiol. 1990, 11:511-517.

- AGOSIN, E.; JARPA, S.; ROJAS, E.; ESPEJO, E. Solid state fermentation of pine sawdust by selected brown-rot fungi. En: Enzyme Microb. Technol. 1989, 11:511-517.

- GANDINI, A. Les lignines et leur utilisation dans les matériaux macromoléculaires. En: Initiation à la chimie et à la physicochimie macromoléculaires. 2002, 13:57-62.

- HOJAS, M. S. Bioconversión de eucaliptus explotado. Uso en resinas fenólicas modificadas. Santiago: Pontificia Universidad Católica de Chile, 1999. (Tesis de Doctorado).

- HIGUCHI, T. Lignin structure and morphological distribution in plant cell walls. En: KIRK, T.K.; HIGUCHI, T.; CHANG, H.M. Lignin biodegradation; microbiology, chemistry, and potential applications. Vol.1. Boca Raton: CRC Press, 1980. pp1-19.

- KIRK, T.K.; CONNORS, W.J.; ZEIKUS, J. Requirement for a growth sustrate during lignin decomposition by twoo wood rothing fungi. En: Appl. Envir. Microbiol.1976, 32:192-194.

- LOPRETTI, M. Sistemas enzimáticos de hongos y bacterias modificadores de lignina. Montevideo: Facultad de Ciencias Universidad de la República, 1999. (Tesis de Doctorado).

- LOPRETTI, M.; CARLOMAGNO, M.; GERVACIO, S.; GANDOMENICO, A. Enzymatic production of phenols from wastes of the paper Industry. En: Biomass of Energ and Ind. 2004:1951-1954.

- LOWRY, O.II.; ROSEHROUGH, N.J.; FARR, A.; RANDALL, R.J. Protein measurement with the Folin phenol reagent. En: Biol. Chem. 1951, 193:265-275.

- TIEN, M.; KIRK, T.K. Lignin-degradating enzyme from Phanerochaete Chrysosporium: purification, characterization and catalytic properties of a unique H2O2-requiring oxygenase. En: Proc. Nat. Acad. Sci. 1984, 81:2280-2284.

- VENICA, A. Transformación de lignina en productos de alto valor agregado. [s.1.]: CYTED,1997.

- VICUÑA, R. Bacterial degradation of lignin. En: Enzyme Microbiol. Technol.,1988. 10:646-655. 